\title{
Aplicação noturna de inseticidas para controle do percevejo- preto em amendoim
}

Submetido - 31 jul. $2020 \quad$ Aprovado -05 set. $2020 \quad$ Publicado - 14 out. 2020

http://dx.doi.org/10.17648/sas.v1i2.70

Rodolfo de Oliveira Rincão
Graduando em Agronomia - Unirp, São José do Rio Preto, SP, rodolforincao@gmail.com.

Rodolfo da Silveira Pivaro (D)

Graduando em Agronomia - Unesp, Dracena, SP, rodolfo_pivaro@hotmail.com.

Alessandro Martins Xavier ${ }^{(D)}$

Graduando em Agronomia - Unilago, São José do Rio Preto, SP, alessandro.saopaulo56@gmail.com.

Maycon Ferraz iD

Eng. Agrônomo-Brumau, Catanduva, SP, maycon.ferraz96@hotmail.com.

Renan Agostinho Domene (D)

Graduando em Agronomia - Unifipa, Catanduva, SP, renanagostinho@hotmail.com.

Marcos Doniseti Michelotto (iD)

Dr., Pesquisador Científico - Apta, Polo Centro Norte, Pindorama, SP, marcos.michelotto@sp.gov.br.

\section{RESUMO}

O percevejo-preto, Cyrtomenus mirabilis (Hemiptera: Cydnidae), devido os prejuízos causados, tem se mostrado como uma praga de solo importante na cultura do amendoim no Brasil. Estudos realizados em laboratório mostraram que alguns inseticidas são eficientes para seu controle. Entretanto, a forma de aplicação pode ter grande interferência na sua eficácia. Assim, objetivou-se avaliar a eficácia de inseticidas aplicados à noite na ocorrência e danos do percevejo-preto em amendoim. O experimento foi instalado na Apta, Polo Centro Norte, em Pindorama - SP. O delineamento experimental foi em blocos casualizados, com quatro repetições. Os tratamentos foram: Regent ${ }^{\circledR}$ Duo $\left.\left(1.000 \mathrm{~mL} \mathrm{ha}^{-1} \text { e } 200 \mathrm{~mL} \mathrm{ha}\right)^{-1}\right)$, Sabre $\AA(1.000 \mathrm{~mL}$ $\left.h^{-1}\right)$, Meta Turbo SC (1.000 mL ha-1), Fastac ${ }^{\circledR}$ Duo (1.000 $\left.\mathrm{mL} \mathrm{ha}^{-1}\right)$ e uma testemunha. A aplicação de Regent ${ }^{\circledR}$ Duo (1.000 mL ha-1) foi realizada no sulco de semeadura e as demais aplicações foram realizadas aos 82 dias após semeadura à noite (20h00 horas). Os parâmetros avaliados foram o número de percevejos por trincheira, o número de grãos com sintomas de ataque e o resíduo dos inseticidas nos grãos. Os tratamentos Regent® Duo (200 $\left.\mathrm{mL} \mathrm{ha}^{-1}\right)$ e Sabre® ${ }^{\circledR}\left(1000 \mathrm{~mL} \mathrm{ha}^{-1}\right)$ apresentaram eficiência de controle e redução dos danos acima de $87 \%$. Os inseticidas nas doses e nas condições avaliadas não apresentam resíduo nos grãos de amendoim na colheita.

Palavras-chave: Arachis hypogeae L., Cyrtomenus mirabilis, Praga de solo, Resíduo de inseticidas.

\section{Night application of insecticides to burrower bug control in peanuts}

\section{ABSTRACT}

The burrower bug, Cyrtomenus mirabilis (Hemiptera: Cydnidae) has been shown to be an important soil pest in the peanut crop in Brazil by damage caused. Laboratory studies have shown that some insecticides are efficient for control. However, the form of application can have great interference in its effectiveness. Thus, the objective was to evaluate the 
effectiveness of insecticides applied at night in the occurrence and damage of burrower bug in peanuts. The experiment was assay at Apta, Polo Centro Norte, in Pindorama - SP. The experimental design was in randomized blocks, with four replications. The treatments were:

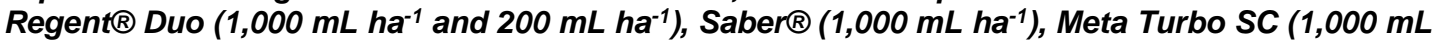
$\left.\mathrm{ha}^{-1}\right)$, Fastac $\circledast$ Duo $\left(1,000 \mathrm{~mL} \mathrm{ha} \mathrm{s}^{-1}\right)$ 1) and a witness. The application of Regent $\circledast$ Duo $(1,000 \mathrm{~mL}$ $\left.h^{-1}\right)$ was carried out in furrow and the other applications were carried out at 82 days after sowing at night (8:00 pm). The parameters evaluated were the number of burrower bug per trench, the number of kernels with symptoms of attack and the residue of insecticides in the

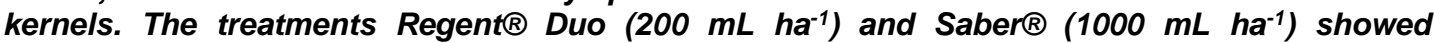
efficiency of control and damage reduction above $87 \%$. The insecticides in the doses and evaluated conditions do not present residues of insecticides in the peanut kernels at harvest.

Keywords: Arachis hypogeae L.; Cyrtomenus mirabilis; Soil pest; Pesticide residue.

\title{
Aplicación nocturna de insecticidas para el control del chinche en el maní
}

\begin{abstract}
RESUMEN
El chinche, Cyrtomenus mirabilis (Hemiptera: Cydnidae), debido al daño causado, ha demostrado ser una plaga importante del suelo en el cultivo de maní en Brasil. Los estudios de laboratorio han demostrado que algunos insecticidas son efectivos para su control. Sin embargo, la forma de aplicación puede tener una gran interferencia en su efectividad. Por lo tanto, el objetivo fue evaluar la efectividad de los insecticidas aplicados por la noche en la aparición y daño del chinche en el maní. El experimento se instaló en Apta, Polo Centro Norte, en Pindorama - SP. El diseño experimental fue en bloques al azar, con cuatro repeticiones. Los tratamientos fueron: Regent ${ }^{\circledR}$ Duo $\left(1,000 \mathrm{~mL} \mathrm{ha}^{-1}\right.$ y $\left.200 \mathrm{~mL} \mathrm{ha}^{-1}\right)$, Saber® $\left(1,000 \mathrm{~mL} \mathrm{ha}^{-1}\right)$, Meta Turbo SC $\left(1,000 \mathrm{~mL} \mathrm{ha}^{-1}\right)$, Fastac ${ }^{\circledR}$ Duo $\left(1,000 \mathrm{~mL} \mathrm{ha}^{-1}\right)$ 1) y un testigo. La aplicación de Regent ${ }^{\circledR}$ Duo $\left(1,000 \mathrm{~mL} \mathrm{ha}{ }^{-1}\right)$ se realizó en el surco de siembra y las otras aplicaciones se realizaron a los 82 días después de la siembra en la noche $(8: 00$ pm). Los parámetros evaluados fueron el número de chinches por zanja, el número de granos con síntomas de ataque y el residuo de insecticidas en los granos. Los tratamientos Regent ${ }^{\circledR}$ Duo $\left(200 \mathrm{ml} \mathrm{ha}^{-1}\right)$ y Sabre $\AA\left(1000 \mathrm{ml} \mathrm{ha}^{-1}\right)$ mostraron una eficacia de control y una reducción de daños por encima del $87 \%$. Los insecticidas en las dosis y en las condiciones evaluadas no presentan residuos en los granos de maní en la cosecha.
\end{abstract}

Palabras clave: Arachis hypogeae L.; Cyrtomenus mirabilis; Plaga del suelo; Residuo de insecticida.

\section{Introdução}

O percevejo-preto, Cyrtomenus mirabilis (Perty, 1830) (Hemiptera: Cydnidae), possui distribuição em praticamente toda a América continental, sendo considerada uma espécie importante nas culturas de amendoim no Peru, Paraguai, Argentina e Brasil (FROESCHNER 1960, GALLO et al. 2002).

Adultos de C. mirabilis e suas fases jovens vivem no solo, incluindo sua oviposição. Em amendoim, seus danos estão relacionados ao ataque em vagens na fase de desenvolvimento dos grãos, na qual ninfas e adultos inserem o estilete de seu aparelho bucal, atingindo os grãos em 
desenvolvimento. Ao se alimentarem dos grãos, eles tornam-se manchados impróprios para comercialização (RIIS et al., 2005).

Inseticidas testados em laboratório mostraram boa eficiência de controle (RINCÃO et al., 2019). No entanto, em função de seu hábito subterrâneo, pulverizações foliares de inseticidas apresentam pouca ou nenhuma eficiência de controle e até o momento não há inseticidas registrados para o controle desta praga em amendoim para as nossas condições. Nos Estados Unidos, uma das poucas opções de inseticida para controle de Pangaeus bilineatus (Say) que causa similar em amendoim é o clorpirifós (Lorsban® $15 \mathrm{G}$, na dosagem de 2,24 kg de i.a. ha-1) na fórmula granulada, aplicado em faixa sobre as plantas de amendoim (CHAPIN \& THOMAS, 2003).

Dessa forma torna-se importante a busca por alternativas de controle, de fácil adoção pelos produtores e que causem o menor impacto possível ao meio ambiente e aos consumidores.

Uma possibilidade é a aplicação noturna que tem sido avaliada em algumas situações como, por exemplo, a diminuição do impacto de inseticidas em abelhas (BYRNE \& WALLER, 1990) ou para melhorar a eficiência na aplicação por apresentar melhores condições climáticas de umidade relativa do ar, temperatura e vento sendo, portanto, mais adequados à aplicação de gotas finas (ANTONIASSI \& BOLLER, 2011).

Para o percevejo-preto, a aplicação noturna pode ser uma possibilidade viável por dois aspectos. Como os folíolos das plantas de amendoim se fecham a noite, a possibilidade da calda atingir o solo facilitando sua penetração é maior. Outro aspecto está relacionado ao hábito do inseto, na qual ninfas nos últimos estágios e adultos saem do solo e se movimentam na superfície do solo à noite (CHAPIN \& THOMAS, 2003; LIMA et al., 2018) aumentando as chances de contato com o inseticida.

Dessa forma, o objetivo deste trabalho foi avaliar a eficácia de inseticidas aplicados à noite na ocorrência e danos do percevejo-preto em amendoim. 


\section{Material e métodos}

Para avaliação dos tratamentos foi instalado um experimento em área experimental da Apta, Polo Centro Norte em Pindorama, estado de São Paulo, com histórico de ocorrência do inseto em safras anteriores.

O delineamento experimental adotado foi em blocos casualizados, com 4 repetições. Os tratamentos são apresentados na Tabela 1.

Cada parcela foi constituída de quatro linhas de 5 metros de comprimento, com espaçamento entre linhas de $0,9 \mathrm{~m}$. A semeadura foi realizada manualmente no dia 09/11/2019 e na densidade de 20 sementes por metro, utilizando a cultivar IAC OL3. As sementes foram previamente tratadas com fungicida registrado para controle de doenças redutoras de estande.

Tabela 1. Inseticidas, ingredientes ativos, dose e época/local de aplicação para controle do percevejo-preto. Safra 2019/20.

\begin{tabular}{|c|c|c|c|c|}
\hline Tratamento & Ingrediente Ativo & $\begin{array}{l}\text { Dosagem } \\
\text { (p.c.) }\end{array}$ & $\begin{array}{l}\text { Dosagem } \\
\text { (i.a.) }\end{array}$ & $\begin{array}{l}\text { Época/Local } \\
\text { de aplicação }\end{array}$ \\
\hline 1. Testemunha & - & - & & - \\
\hline 2. Regent $\circledast$ Duo & $\begin{array}{c}\text { Fipronil }+ \\
\text { Alfacipermetrina }\end{array}$ & $1.000 \mathrm{~mL} \mathrm{ha}^{-1}$ & $\begin{array}{l}180 \mathrm{~g} \mathrm{ha}^{-1}+ \\
120 \mathrm{~g} \mathrm{ha}^{-1}\end{array}$ & SS \\
\hline 3. Regent $\AA$ Duo & $\begin{array}{c}\text { Fipronil }+ \\
\text { Alfacipermetrina }\end{array}$ & $200 \mathrm{~mL} \mathrm{ha}^{-1}$ & $\begin{array}{l}36 \mathrm{~g} \mathrm{ha}^{-1}+ \\
24 \mathrm{~g} \mathrm{ha}^{-1}\end{array}$ & $\begin{array}{l}82 \text { DAS / } \\
\text { Foliar* }\end{array}$ \\
\hline 4. Sabre® & Clorpirifós & $1.000 \mathrm{~mL} \mathrm{ha}^{-1}$ & $450 \mathrm{~g} \mathrm{ha}^{-1}$ & $\begin{array}{l}82 \text { DAS / } \\
\text { Foliar* }\end{array}$ \\
\hline 5. Meta Turbo SC & $\begin{array}{l}\text { Metarhizium } \\
\text { anisopliae }\end{array}$ & $1.000 \mathrm{~mL} \mathrm{ha}^{-1}$ & $\begin{array}{l}\text { Mín. de } 1,0 x \\
10^{8} \text { propágulos } \\
\text { viáveis } / \mathrm{mL}\end{array}$ & $\begin{array}{l}82 \text { DAS / } \\
\text { Foliar* }\end{array}$ \\
\hline 6. Fastac $\AA^{8}$ Duo & $\begin{array}{c}\text { Acetamiprido }+ \\
\text { Alfa-cipermetrina }\end{array}$ & $1.000 \mathrm{~mL} \mathrm{ha}^{-1}$ & $\begin{array}{l}100 \mathrm{~g} \mathrm{ha}^{-1}+ \\
200 \mathrm{~g} \mathrm{ha}^{-1}\end{array}$ & $\begin{array}{l}82 \text { DAS / } \\
\text { Foliar* }\end{array}$ \\
\hline
\end{tabular}

$S S=$ pulverização sobre as sementes no sulco de semeadura; DAS= Dias após semeadura; *= aplicação às 20:00 horas.

A aplicação do Regent Duo no sulco de semeadura foi realizada com pulverizador costal elétrico, dotado de ponta de pulverização do tipo leque e com volume de 100 litros ha-1. A aplicação noturna foi realizada com mesmo equipamento, dotada de ponta de pulverização do tipo jato sólido e com volume de calda de 250 litros ha- ${ }^{-1}$ aos 82 DAS (29/01/2020) às 20:00 horas. Importante ressaltar que a aplicação se deu após uma precipitação de 58,4 $\mathrm{mm}$ e no dia seguinte ocorreu nova precipitação de 15,7 mm. Assim, a 
pulverização ocorreu em solo bastante encharcado e isso facilitou a distribuição dos inseticidas.

O experimento foi conduzido realizando-se o controle de pragas da parte aérea e de doenças fúngicas foliares de acordo com as recomendações para a cultura (GODOY et al., 2014).

\section{Parâmetros avaliados}

Aos 132 DAS (18/03/2020) foram realizadas trincheiras para a quantificação dos percevejos no solo nos diferentes tratamentos. Em cada parcela foi aberta duas trincheiras de $0,3 \mathrm{~m}$ de comprimento $\times 0,3 \mathrm{~m}$ de largura $X 0,15 \mathrm{~m}$ de profundidade, utilizando uma forma. Posteriormente, $\mathrm{o}$ solo coletado foi cuidadosamente lavado com o auxílio de água e peneira e os percevejos presentes foram contabilizados e expressos em percevejos por trincheira.

Concomitantemente, foi realizada a amostragem de $0,5 \mathrm{~m}$ de linha de plantas, que foram avaliadas quanto ao número de vagens e grãos. As vagens foram armazenadas em freezer (temperatura de $\pm 3^{\circ} \mathrm{C}$ ) e posteriormente avaliadas para quantificação do número de grãos apresentando sinais de ataque do percevejo e expressos em porcentagem de grãos com sintomas de danos.

Além disso, por ocasião da colheita, uma amostra de 600 gramas de grãos secos ( $7 \%$ de umidade) de cada parcela, foi encaminhada para 0 laboratório JLA Brasil que procedeu a análise de resíduos dos inseticidas avaliados.

Os dados de insetos por trincheira e do percentual de grãos com danos visuais foram submetidos à análise de variância pelo teste $\mathrm{F}$ e as médias comparadas pelo teste Tukey a $5 \%$ de probabilidade. A porcentagem de eficiência de controle (EC) e eficiência de redução do dano (ER) foi calculada, conforme Abbott (1925). Além disso, dados de precipitação disponibilizados pelo Portal Agrometeorológico e Hídrológico do Estado de 
São Paulo (CIIAGRO, 2020) foram utilizados para comparação com safra no ano anterior.

\section{Resultados e discussão}

A ocorrência deste inseto é extremamente variável no solo. É extremamente difícil ter uma distribuição homogênea que permita a instalação de experimentos visando seu controle.

Dito isto, apesar da variabilidade, foi possível observar diferenças significativas tanto no número de percevejos quanto nos seus danos aos grãos de amendoim.

Para o número médio de percevejos-preto por trincheira observou-se diferença significativa entre os tratamentos utilizados (Figura 2). Na testemunha, observou-se em média 25,8 percevejos por trincheira não diferindo do tratamento Fastac Duo com 38,3 percevejos por trincheira. Já os tratamentos com menor infestação foram o Regent Duo na dosagem de 200 $\mathrm{ml} \mathrm{ha}^{-1} \mathrm{em}$ aplicação noturna, Regent Duo (1000 ml ha-1) aplicado no sulco de semeadura e Sabre (1000 ml ha-1) em aplicação noturna (Figura 2).

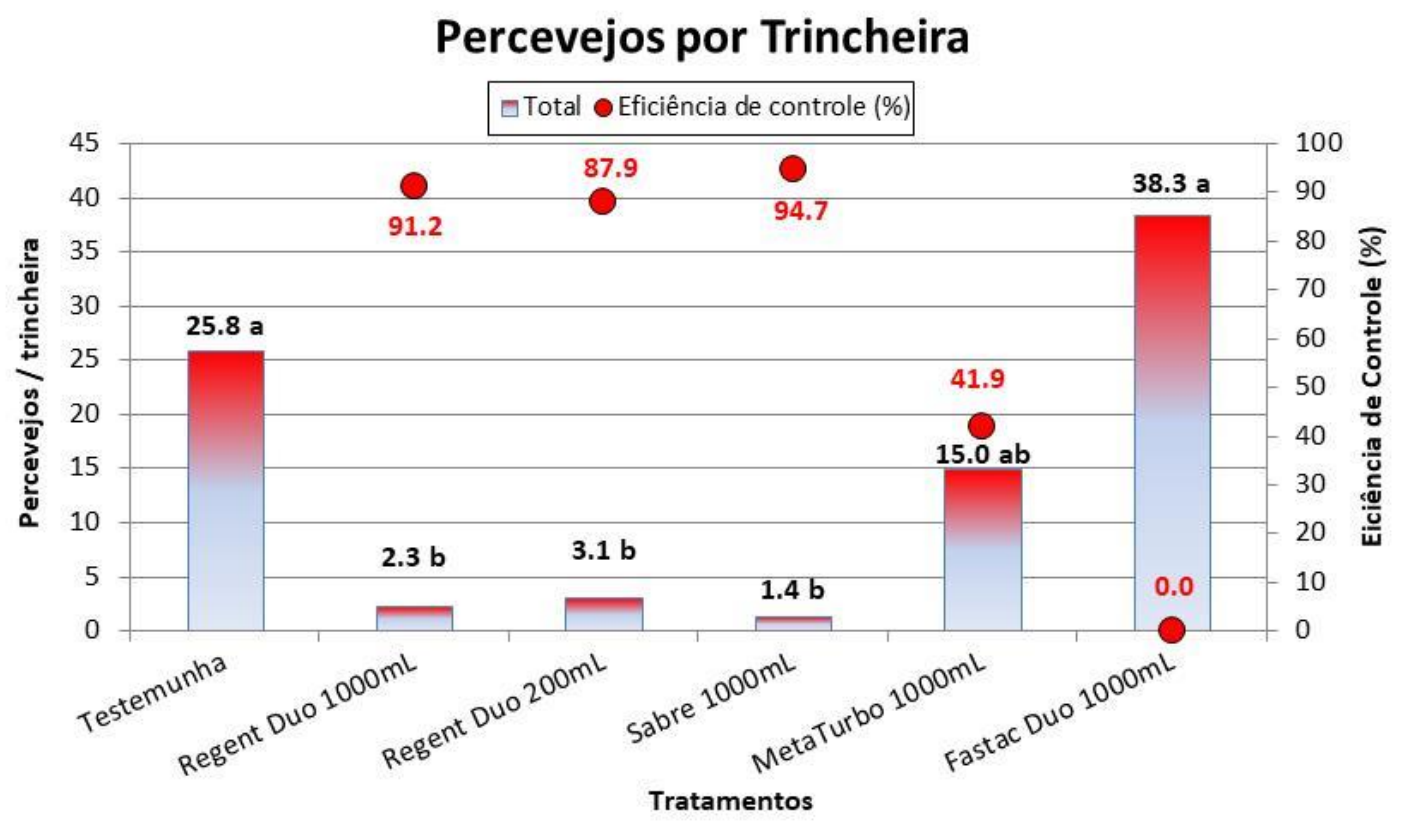

Figura 2. Número médio de percevejos (adulto + ninfa) por trincheira e eficiência de controle (\%) em diferentes tratamentos utilizados em amendoim. Pindorama, safra 2019/20. Médias seguidas de mesma letra não 
diferem entre si pelo teste de Tukey a 5\% de probabilidade ( $\left.F=8,28^{* *} ; C V=45,78 \%\right)$. ${ }^{*}$ siginifcativo a $1 \%$.

Estes três tratamentos apresentaram uma eficiência de controle acima de $87 \%$, o que é considerado alto quando se trata de insetos de solo. Para o percevejo-castanho, Scaptocoris castanea (Hemiptera: Cydnidae), que hábito subterrâneo e deslocamento no perfil do solo semelhante ao percevejo-preto, essas características constituem fatores limitantes para seu controle (CECCON et al., 2004).

Quando avaliado em laboratório, Regent Duo na dosagem de 1000 $\mathrm{ml}$ ha $^{-1}$ também apresentou alta mortalidade tanto de ninfas quanto de adultos do percevejo-preto (RINCÃO et al., 2019). No entanto, em condições de campo, na safra 2018/19, esta dosagem apesar de controlar satisfatoriamente o percevejo-preto (POLLI et al., 2019), apresentou resíduo de fipronil (um dos ingredientes ativo) próximo do Limite Máximo de Resíduo (LMR) permitido para a molécula estabelecido pela União Européia e, portanto não seria recomendado.

Com relação ao percentual de grãos com sintomas visuais de danos do percevejo-preto, observou-se diferença significativa entre os tratamentos (Figura 3) seguindo a mesma tendência observada para o número de percevejo por trincheira.

$\mathrm{Na}$ testemunha, a média de grãos com sintomas visuais de danos foi de 16,0\%. O inseticida biológico, Meta Turbo e o inseticida sintético, Fastac Duo apresentaram valores intermediários. Já os tratamentos Regent Duo aplicado no sulco de semeadura ou em aplicação noturna e o inseticida Sabre foram os mais eficientes na redução dos danos (Figura 3).

Os resultados semelhantes observados para número de insetos e danos nos grãos foi confirmado por uma análise de correlação positiva e significativa entre ambos de $0,83794^{\star *}(P<0,0001)$.

Os resíduos nos grãos de amendoim foram realizados para todos os ingredientes ativos presentes em todos os inseticidas utilizados no experimento e nenhuma das moléculas nas dosagens utilizadas foi 
detectada nas análises. Mesmo a dosagem mais alta de Regent Duo (1000 $\mathrm{ml} \mathrm{ha}^{-1}$ ) apresentou resíduo de Fipronil e este resultado possivelmente está relacionado às condições climáticas, principalmente precipitação.

$\mathrm{Na}$ safra 2019/20, a precipitação durante o período entre a semeadura e colheita do experimento foi de $886,5 \mathrm{~mm}$ acumulados, sendo acumulados 645,7 mm até a data de aplicação (83 DAS). Já em 2018/19, a precipitação acumulada no período foi de $662,2 \mathrm{~mm}$, ou seja, $25,3 \%$ menor (CIIAGRO, 2020).

Além disso, o que chama mais atenção é sobre o número de dias sem chuva $(<5 \mathrm{~mm})$ durante o ciclo. Enquanto em 2019/20 tivemos 89 dias sem chuva, em 2018/19 o número de dias sem chuva chegou a 130 (CIIAGRO, 2020).

Essas diferenças na precipitação e consequentemente na umidade do solo podem fazer toda a diferença na eficácia de controle da praga pelo inseticida e também no resíduo dessas moléculas nos grãos de amendoim, sendo necessários novos estudos que possam comprovar esta hipótese.

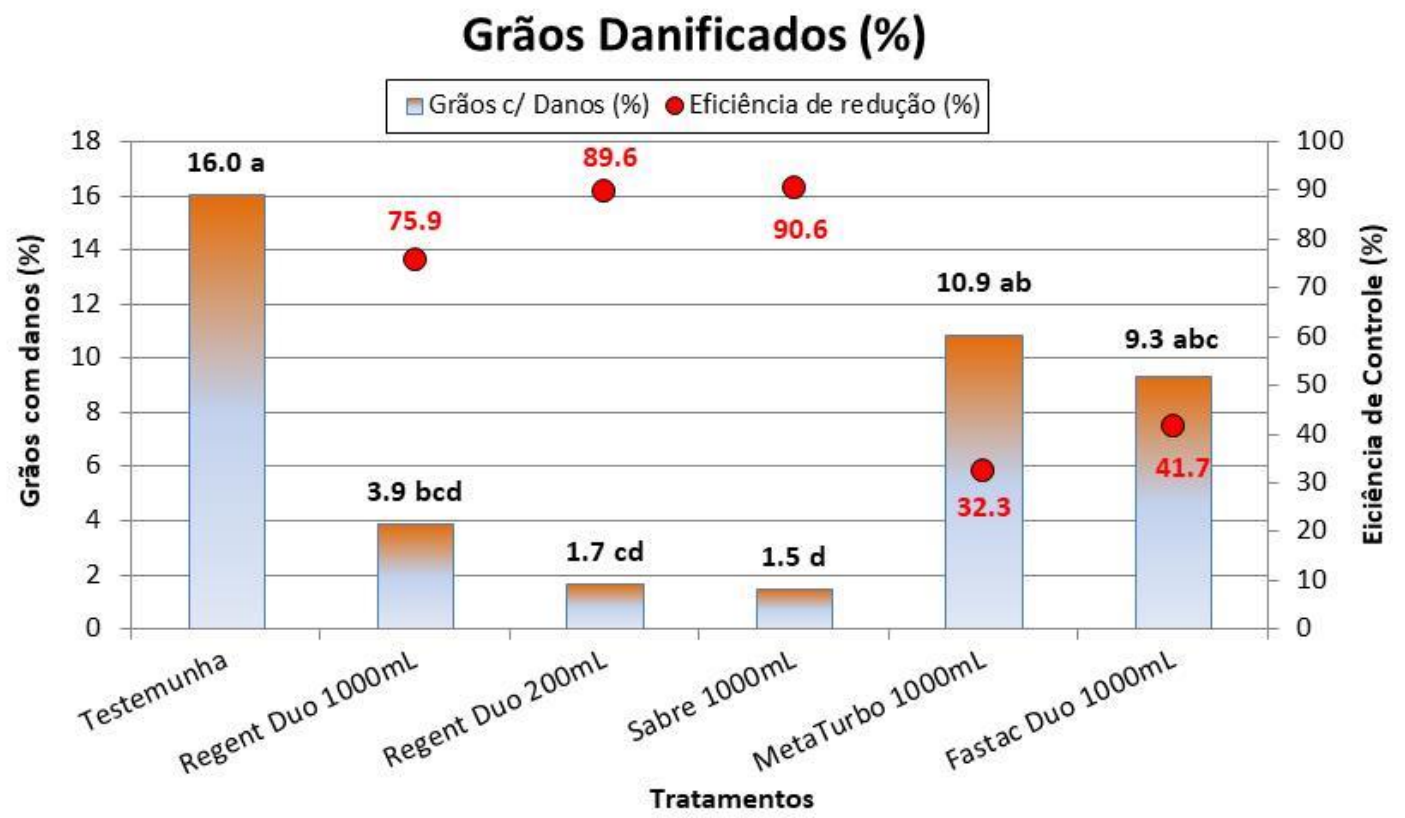

Figura 3. Grãos com sintomas de danos (\%) e eficiência de redução (\%) em diferentes tratamentos utilizados em amendoim. Pindorama, safra 2019/20. Médias seguidas de mesma letra não diferem entre si pelo teste de Tukey a 5\% de probabilidade $\left(F=8,59^{* *} ; C V=33,72 \%\right)$. ${ }^{* *}$ siginifcativo a $1 \%$. 


\section{Conclusões}

A aplicação noturna do Regent Duo na dosagem de $200 \mathrm{~mL} \mathrm{ha}^{-1}$ dos 80 aos 90 DAS é eficiente para controle do percevejo sendo necessário seu registro. A aplicação noturna de Sabre na dosagem de $1000 \mathrm{~mL} \mathrm{ha}^{-1}$ dos 80 aos 90 DAS é eficiente para controle do percevejo sendo necessário seu registro. Na forma e dosagens utilizadas os inseticidas não apresentam resíduos nos grãos de amendoim.

\section{Agradecimentos}

Os autores agradecem ao CNPq pela bolsa de produtividade DT ao último autor e às Empresas Amenco, Balsamo, Beatrice, Casul, Copercana, Coplana, Mars Brasil e Terra Nuts pelo aporte financeiro ao projeto através da Fundag. 


\section{Referências}

ANTUNIASSI, U.R.; BOLLER, W. Tecnologia de aplicação para culturas anuais. Passo Fundo: Aldeia Norte; Botucatu: FEPAF, 2011. p.221-229.

BYRNE, D.N.; WALLER, G.D. Comparison of honey bee (Hymenoptera: Apidae) mortality as a result of diurnal and nocturnal applications of dimethoate. Journal of Economic Entomology 83: 1267-1270, 1990. https://doi.org/10.1093/jee/83.4.1267.

CECCON, G.; RAGA, A.; DUARTE, A.; SILOTO, R. Efeito de inseticidas na semeadura sobre pragas Iniciais e aprendizagem de milho safrinha na planta direta. Bragantia, v.63, n.2, p.227-237, 2004. Disponível em: https://www.redalyc.org/articulo.oa?id=90863208

CIIAGRO. Portal Agrometeorológico e Hídrológico do Estado de São Paulo. Disponível em: <http://www.ciiagro.org.br/> Acesso em: 17 jul. 2020.

FROESCHNER, R.C. Cydnidae of the Western Hemisphere. Proceedings of the United States National Museum, v.111, p.337-680, 1960.

GALLO, D.; NAKANO, O.; NETO, S.S.; CARVALHO, R.P.L.; BAPTISTA, G.C.; FILHO, E.B.; PARRA, J.R.P.; ZUCCHI, R.A.; ALVES, S.B.; VENDRAMIM, J.D.; MARCHINI, L.C.; LOPES, J.R.S.; OMOTO, C. Entomologia agrícola. 10.ed. Piracicaba: FEALQ, 2002. 920p.

GODOY, I.J.; BOLONHEZI, D.; MICHELOTTO, M.D.; FINOTO, E.L.; KASAI, F.S.; FREITAS, R.S. Amendoim - Arachis hypogaea L. In: AGUIAR, A.T.E.; GONÇALVES, C.; PATERNIANI M.E.A.G.Z.; TUCCI, M.L.S.; CASTRO, C.E.F. (Eds.). Instruções agrícolas para as principais culturas econômicas. $7^{\mathrm{a}} \mathrm{Ed}$. rev. e atual. Campinas: Instituto Agronômico, 2014. p. 22-27p. (Boletim IAC, № 200).

LIMA, Í.A.; FERRAZ, M.; FREITAS, R.S; BOLONHEZI, D.; GODOY, I.J.; MICHELOTTO, M.D. 2018. Flutuação populacional do percevejo-preto-em amendoim através de armadilhas de queda. Em: Anais do Encontro sobre a Cultura do Amendoim. Campinas: Galoá. 2018. Disponível em: <https://proceedings.science/encontro-amendoim-2018/papers/flutuacaopopulacional-do-percevejo-preto-em-amendoim-atraves-de-armadilhas-dequeda>. Acessado: 17 jul. 2020.

POLLI JUNIOR, P.C.; RINCÃO, R.O.; FERRAZ, M.; FREITAS, R.S.; GODOY, I.J.; MICHELOTTO, M.D. 2019. Fontes de enxofre no controle do percevejo-preto, Cyrtomenus mirabilis (Perty, 1836) (Hemiptera: Cydnidae) em amendoim. Em: Anais do XVI Encontro Sobre a Cultura do Amendoim. Campinas: Galoá. 2019. Disponível em: <https://proceedings.science/encontro-amendoim-2019/papers/fontes-deenxofre-no-controle-do-percevejo-preto--cyrtomenus-mirabilis--perty--1836--hemiptera--cydnidae--em-amendoim> . Acessado: 16 jul. 2020. 
RINCÃO, R.O.; FERRAZ, M.; POLLI JUNIOR, P.C.; FREITAS, R.S.; GODOY, I.J.; MICHELOTTO, M.D.. 2019. Eficiência de inseticidas no controle de percevejo-preto, Cyrtomenus mirabilis (Perti, 1830) em condições de laboratório. Em: Anais do XVI Encontro Sobre a Cultura do Amendoim. Campinas: Galoá. 2019. Disponível em: $<$ https://proceedings.science/encontro-amendoim-2019/papers/eficiencia-deinseticidas-no-controle-de-percevejo-preto--cyrtomenus-mirabilis--perti-1830--em-condicoes-de-laboratorio> Acesso em: 16 jul. 2020.

RIIS, L.; BELOTTI, A.C.; ARIAS, B. Bionomics and population growth statistics of Cyrtomenus bergi (Hemiptera: Cydnidae) on different host plants. Florida Entomologist, v.88,

p.1-10, 2005. https://doi.org/10.1093/jee/96.6.1905. 